\title{
LA 'MEJORA' COMO UNA FORMA DE CORREGIR EL IGUALITARISMO CASTELLANO. COMARCA DE SAHAGÚN, SIGLO XVIII
}

\author{
Francisco Javier LAGARTOS PACHO \\ Universidad de León
}

\begin{abstract}
RESUMEN: Estudio y análisis, mediante la utilización de las escrituras de testamentos, particiones de bienes y escrituras de mejora, de los diferentes temas relacionados con la herencia familiar, su importancia como una forma de distribución de la propiedad una vez fallecido el progenitor y la repercusión que tiene la introducción de la mejora post mortem en el reparto igualitario vigente en el derecho castellano a lo largo del siglo XVIII en Tierra de Campos Leonesa (Comarca de Sahagún, León).

PALABRAS CLAVE: Partijas o particiones de bienes, testamento, mejora post mortem, herencia, Sahagún, Siglo XVIII.

ABSTRACT: This paper analyses XVIII century wills in the region of León known as Tierra de Campos (Sahagún) in order to approach issues related to family heritage and their importance as a way to distribute property after de death of the head of a family. It also deals with the introduction of post mortem betterment and its influence on the equalitarian distribution of assets which was in force in Castilian law at that time.
\end{abstract}

KEYWORDS: Share-out-deeds, post mortem, testament betterment, inherance, Sahagún, $18^{\text {th }}$ century.

Dentro de las estructuras que conforman el andamiaje de una sociedad, se encuentra el ámbito sociodemográfico y, dentro de éste, los aspectos relacionados con la familia que constituirán el objeto de nuestro estudio. El hecho social como tal, en la historiografía de nuestro país, es de reciente difusión, y los aspectos referentes a la familia, como parte de este hecho social, también lo son ${ }^{1}$. El estudio, en España, del ámbito social sigue en todo momento parámetros europeos. Caben

\footnotetext{
${ }^{1}$ Durante los últimos 150 años se ofrecía una explicación unidireccional en la que el proceso de cambio y transformación partía de la disolución de la solidaridad familiar, las relaciones de parentesco y la autoridad familiar para dar paso a un modelo nuclear, donde el individualismo y la independencia eran las tónicas dominantes. CHACON JiMÉNEZ, F. (1998). «Propuestas teóricas y organización social desde la historia de la familia en la España Moderna». Studia Histórica. Vol.18. Salamanca.
} 
destacar las aportaciones realizadas por Francisco Chacón Jiménez y su grupo que, desde el Seminario de la Familia y Elites de Poder en el Reino de Murcia de la Universidad de Murcia, nos ofrecen una nueva visión de la familia con la aparición de conceptos como reproducción social y estrategia ${ }^{2}$. Se produce así, una renovación metodológica de la Historia Social y de la Familia en España con la introducción de nuevos campos de investigación: el valor del matrimonio en la sociedad, la conflictividad generada a partir del enlace matrimonial a la muerte de los progenitores, el aspecto económico-patrimonial de la familia, los modos de pensamiento y sentimiento de ese núcleo familiar: la honra, el valor de la palabra dada, los matrimonios clandestinos, la educación, el amor, la ilegitimidad, etc. que marcarán un antes y un después en este tipo de estudios. Así pues, será en este último tercio del siglo XX, cuando se asiste a una verdadera renovación de los conceptos historiográficos postulados hasta los '70 que a España no llegará hasta los ' 80 con los mismos problemas que en el resto de Europa ${ }^{3}$.

Si partimos de que la familia constituye la célula básica de una sociedad, el conocimiento y estudio de ella, nos lleva a comprender mejor el funcionamiento de la estructura social de una zona. Pero la institución familiar comprende infinidad de ámbitos de estudio: herencia, relaciones de parentesco, consaguinidad, estrategias y alianzas matrimoniales, etc., que son necesarios entender para un buen conocimiento de la misma. Es, por esta razón, por la que intentaré explicar dos de

2 Algunos de los títulos de este autor son: CHACON JiMÉNEZ, F. (1998). «Propuestas teóricas y organización social desde la historia...», Op. cit., (1990). «La Familia española: una historia por hacer», en CHACón JiMÉNEZ, F. (Ed.). Historia social de la Familia en España. Alicante. pp. 13-30.

${ }^{3}$ Sería parte de un trabajo más extenso citar la enorme producción que desde esa época existe, pero a pesar de ello citaremos algunos de los ejemplos más destacados. Como ya dijimos, uno de los impulsores de la Historia de la Familia en España es el profesor Francisco Chacón Jiménez desde el Seminario Familia y Elite de Poder en el reino de Murcia. Siglos XV-XIX de la Universidad de Murcia, «La Familia en España. Siglos XVI-XVII", en Historia 16, 57, 1981, PÉrez MoredA, V. (1986). «Matrimonio y Familia. Algunas consideraciones sobre el modelo matrimonial en la Edad Moderna». Boletín de la Asociación de Demografía Histórica, Vol. IV, n ${ }^{\circ}$, BuRGo LóPEZ, Mª ${ }^{\mathrm{a}}$. (1984). «Niveles sociales y relaciones matrimoniales en Santiago y su comarca (1649-1750) a través de las escrituras de dote». II C.M.H.A. Santiago. Pp. 177-199, Rodríguez Ferreiro, H. (1984). «Estructura y comportamiento de la familia rural gallega: Los campesinos del Morrazo en el siglo XVIII». Actas de II coloquio de Metodología Aplicada. La documentación notarial y la Historia I. Universidad de Santiago. En Extremadura destacó el profesor RodRíGUEZ SÁNCHEZ, A. (1991). «Métodos de evaluación de las estrategias familiares en el Antiguo Régimen». Actas del Congreso Fuentes y Métodos de la Historia Local. Zamora. Pp.141-153. En Cataluña destacan los trabajos sobre economías familiares realizados por investigadores como FERRER I ALOS, Ll. (1991). «Estrategias familiares y formas jurídicas de transmisión de la propiedad y el status social». Boletín de la Asociación de Demografia Histórica. Vol. X, nº 3 y (1995). «Notas sobre el uso de la familia y la Reproducción Social». Boletín de la Asociación de la Demografía Histórica. Vol. XIII, nº 1. 
éstos temas: el nombramiento de herederos y la introducción de la mejora en el reparto de la herencia, todo ello enclavado en Tierra de Campos Leonesa (Comarca de Sahagún, sureste de provincia León) durante el siglo XVIII. En este amplio conjunto de conocimientos referentes al ámbito familiar, se abordarán aspectos relacionados con la reproducción social y la herencia utilizando como fuente los testamentos, las escrituras de mejoras y las particiones de bienes ${ }^{4}$, planteándonos abordar en este trabajo los siguientes objetivos: en primer lugar, estudiar el ámbito de las estrategias hereditarias y la transmisión de los bienes y las propiedades y el modo en que ésto se perpetúa en el tiempo y en el espacio, centrándonos en el papel que juega la mejora como instrumento que altera el reparto igualitario. Y, en segundo lugar, poner en relación la legislación vigente y la practica social real para ver en qué medida la fuerza de la costumbre prevalece sobre el derecho castellano.

\section{LA IMPORTANCIA DE LA HERENCIA COMO UNA FORMA DE DISTRIBUCIÓN DE LA PROPIEDAD.}

La familia es un concepto muy amplio y actúa sobre un conjunto de factores que desborda el propio marco de lo cotidiano, de este modo, podemos decir que la familia es una institución viva que se encuentra sometida a un proceso de transformación constante que discurre paralelo al de la sociedad en la cual está inmersa y cuyos cambios deben interpretarse dentro de ese ámbito ${ }^{5}$. La familia es, pues, la institución social a través de la cual se lleva a cabo, no solo la reproducción de todo el sistema, sino también la posibilidad de movilidad, o no, de los distintos grupos sociales ${ }^{6}$. Y es en esta esfera donde debemos fijar la herencia, que pasa a ser uno de los momentos claves en la vida familiar, porque posibilitaba poder incrementar el patrimonio mediante los bienes recibidos por causa del fallecimiento de uno o de los dos progenitores.

Muchas son las formas de distribución de la propiedad ${ }^{7}$, pero en este estudio nos centraremos en los aspectos relativos al nombramiento de los herederos, como una

${ }^{4}$ Para ello se ha utilizado 388 escrituras de testamentos de diferente condición social y de diversas villas y lugares, unido a ello unas cuantas escrituras de mejoras y unas 90 partijas. Archivo Histórico Provincial de León (en adelante AHPL). Sección Protocolos Notariales de Sahagún.

${ }^{5}$ Blanco Villegas, M. J. y otros. (2001). «Caracterización de la dinámica familiar en una comarca natural (La Cabrera, España)». Boletín ADEH, Vol. XIX-I.

${ }^{6}$ Chacón Jiménez, F. Historia social de..., Op. cit.

7 Algunas formas son las siguientes: compraventas, renuncias de legitimas, dotaciones matrimoniales, donaciones intervivos, legados testamentarios, etc., GARCÍA FERNANDEZ, M. 
forma de acceder a la propiedad, y el momento en el que se distorsiona el reparto igualitario de la herencia ${ }^{8}$ con la introducción de las mejoras post mortem.

El testamento es, junto a las particiones de bienes, una de las fuentes imprescindibles para el estudio de los aspectos relacionados con el sistema hereditario 9 .

Según la diversa legislación existente de la época ${ }^{10}$ se determina que el reparto debía de ser igualitario entre todos los hijos fruto del matrimonio ${ }^{11}$. Pero, ¿cómo se fraccionaba la herencia para luego realizar el reparto? Como ya está

(1995). Herencia y Patrimonio familiar en la Castilla del Antiguo Régimen (1650-1834). Efectos socioeconómicos de la muerte y la partición de bienes. Universidad de Valladolid. Pp. 143.

${ }^{8}$ Algunos autores como Llorenç Ferrer i Alós diferencian entre sistemas de transmisión de bienes y sistemas de herencia. El primero se refiere al proceso que se lleva a cabo durante toda la vida con la incorporación de las dotes, donaciones, elección de cónyuge, traspaso de cargos públicos, etc., mientras que el sistema de herencia se refiere a la transmisión de los bienes a la muerte del antiguo poseedor. FERRER I ALÓs, Ll. (1995). "Notas sobre el uso de la familia y la reproducción social". Boletín de la Asociación de Demografia Histórica, Vol. XIII, nº1. pp. 18. Este estudio irá más encaminado a ésta última propuesta ya que se estudia la transmisión de los bienes cuando ha fallecido su antiguo poseedor.

${ }^{9}$ Ley I, Tít. I, Sexta Partida: "Testatio" y "mens" son dos palabras que en latín quieren decir testimonio de las voluntades del hombre. En él se establece la voluntad de quien lo hace, poniendo un heredero y partiendo lo suyo de aquella manera que él tenga por bien. Dos maneras de testamento: "testamento nuncupatiuum" manda que se hace ante siete testigos y "testamento in seriptis" o manda que se hace por escrito. Siete Partidas del sabio rey Don Alfonso el Nono, Glosadas por el Licenciado Gregorio López del Consejo Real de Indias de su Majestad. Andrea de Portonariis (impresor de su Majestad). Salamanca. 1555.

${ }^{10}$ El sistema hereditario castellano estuvo regulado en toda la Edad Media por dos documentos: El Fuero Real y Las Partidas. Ambas dieron origen a la fijación del derecho castellano que se produjo con las Leyes de Toro (1505). Luego se mantuvo, con alguna modificación, en la Novísima Recopilación que realizó Carlos IV (1804) donde se reforma la recopilación publicada por Felipe III en 1567 y se incorporan las pragmáticas, cedulas, decretos, órdenes y resoluciones reales, y otras providencias no recopiladas y expedidas hasta 1804; vid. GACTO FERNANDEZ, E. (1987). «El grupo familiar en le Edad Moderna en los territorios de Mediterráneo Hispánico: Una visión jurídica», en La familia en la Historia de España. Barcelona.

${ }^{11}$ De este forma aparece en la legislación: Cómo debe ser partida la herencia entre los herederos cuando son muchos. La herencia debe ser partida igualmente entre todos pero si el testador quiere dar a uno de ellos algo más debe decir cuanto más. Ley XVII, Sexta Partida. Siete Partidas del sabio rey Don Alfonso..., Op. cit. Además este hecho queda fijado en las Leyes de Toro de 1505 del Derecho Castellano. Véase GaCto Fernandez, E. (1987). El grupo familiar en la Edad Moderna..., Op. cit. 
suficientemente estudiado, el testador castellano dividía la herencia en cinco partes, de las cuales cuatro debe de transmitirla forzosamente a sus descendientes, de ellas dos partes debe repartirlas igualitariamente entre hijos y nietos y la parte restante entre quien estime oportuno: es el denominado tercio de mejora. La quinta parte que faltaba para completar la herencia es lo que conocemos como quinto de libre disposición ${ }^{12}$ y se dedicaba al pago de las mandas piadosas y los gastos destinados al entierro, pudiendo ser legado a alguno de sus herederos la parte de éste que sobrase. De este modo, intentaremos demostrar que ese igualitarismo no era tal, debido a la existencia de dos mecanismos correctores: el quinto de libre disposición y el tercio de mejora, o ambos a la vez, ocasionando la contradicción entre las prescripciones que imponía la ley castellana referentes al igualitarismo y la práctica habitual de la sociedad: ley frente a costumbre.

\section{LOS HEREDEROS DE LOS BIENES DEL DIFUNTO.}

Según las leyes ${ }^{13}$, el heredero debe de ser establecido en el testamento y no en otra escritura pública y será aquí donde aparecerán la/s persona/s instituidas como "únicos y universales herederos" 14 que son a las que van dirigidas todos los bienes una vez descontadas las mandas testamentarias, los legados y todos los gastos propios del funera ${ }^{15}$. Así, en el análisis de las personas instituidas como tales, podemos observar las preferencias de los testadores y el grado de cumplimiento de las leyes vigentes ${ }^{16}$.

12 GaCto FernandeZ, E. (1987). «El grupo familiar en la edad moderna ...», Op. cit. pp. 50 y ss. Véase también la Lib. X, Ley IX (Ley 30 de Toro): Los gastos del funeral se sacan del quinto de los bienes del difunto y no del cuerpo de ellos, en la Novísima Recopilación de la Leyes de España mandada formar por el señor D. Carlos IV, Madrid, 1805. Es una reforma de la recopilación publicada por el Señor Don Felipe III en 1567 y reimpresa en 1775. A ella se incorporan las pragmáticas, cedulas, decretos, órdenes y resoluciones reales, y otras providencias no recopiladas y expedidas hasta 1804 .

${ }^{13}$ Sexta Partida. Ley VII. El establecimiento del heredero debe ser hecho solo en testamento y no en otra escritura. Siete Partidas del sabio rey Don Alfonso el Nono, Glosadas..., Op. cit.

${ }^{14}$ Todo hombre libre puede ser establecido por heredero de otro... . Ley II, Título III de cómo deben ser establecidos los herederos en los testamentos. Siete Partidas del sabio rey Don Alfonso..., Op. cit.

${ }^{15}$ Así es como aparece en un ejemplo tipo de escrituras testamentaria “... cumplido y pagado en el remanente que quedase de todos mis bienes derechos y acciones que me puedan tocar toquen $y$ pertenezcan en cualquiera forma, dejo nombro e instituyo por mis únicos y universales herederos a los dichos..." AHPL, Caja 4437.

${ }^{16}$ Para ello hemos consultado más de 380 testamentos comprendidos entre 1700-1810 y ubicados en Tierra de Campos leonesa que abarcaría unos 84 pueblos con una población alrededor de los 
Los resultados quedan reflejados en el Cuadro 1, para el que hemos realizado una configuración basada en tres grupos principales: casados, solteros y viudos, y dentro de los casados distinguiremos entre casados con hijos y sin hijos con el fin de poder diferenciar y explicar las diversas tendencias, ya que, los resultados tendrán diferente interpretación dependiendo de las condiciones en las que se desarrollen dentro del núcleo familiar ${ }^{17}$.

Cuadro 1: Principales herederos. 1700-1820.

\begin{tabular}{|c|c|c|c|c|c|c|c|c|c|c|}
\hline \multirow[b]{3}{*}{ Categoria de herederos } & \multicolumn{10}{|c|}{ Condición testadores } \\
\hline & \multicolumn{4}{|c|}{$\begin{array}{c}\text { Casado con Casado sin } \\
\text { hijos }\end{array}$} & \multicolumn{2}{|c|}{ Viudos } & \multicolumn{2}{|c|}{ Solteros } & \multicolumn{2}{|c|}{ Total } \\
\hline & $N^{o}$ & $\%$ & $N^{o}$ & $\%$ & $N^{o}$ & $\%$ & $N^{o}$ & $\%$ & $N^{o}$ & $\%$ \\
\hline \multicolumn{11}{|l|}{ Herederos Legítimos } \\
\hline Hijos/As/Nietos & 258 & 100 & 0 & 0 & 6 & 100 & 0 & 0 & 264 & 97,8 \\
\hline Padres & 0 & 0 & 2 & 100 & 0 & 0 & 4 & 100 & 6 & 2,2 \\
\hline Total H. Forzosos & 258 & 99,2 & 2 & 3,1 & 6 & 33,3 & 4 & 10 & 270 & 70,7 \\
\hline \multicolumn{11}{|l|}{ Herederos No Legítimos } \\
\hline Alma & 0 & 0 & 0 & 0 & 0 & 0 & 6 & 16,7 & 6 & 5,4 \\
\hline Primo/A & 0 & 0 & 0 & 0 & 0 & 0 & 4 & 11,1 & 4 & 3,6 \\
\hline Hermanos/As & 0 & 0 & 0 & 0 & 2 & 16,7 & 18 & 50 & 20 & 17,9 \\
\hline Sobrinos/As & 0 & 0 & 6 & 9,7 & 6 & 50 & 4 & 11,1 & 16 & 14,3 \\
\hline Tios/As & 0 & 0 & 2 & 3,2 & 0 & 0 & 2 & 5,6 & 4 & 3,6 \\
\hline Vecinos/As & 0 & 0 & 2 & 3,2 & 4 & 33,3 & 2 & 5,6 & 8 & 7,1 \\
\hline Mujer & 2 & 100 & 26 & 41,9 & 0 & 0 & 0 & 0 & 28 & 25,0 \\
\hline Marido & 0 & 0 & 20 & 32,3 & 0 & 0 & 0 & 0 & 20 & 17,9 \\
\hline Marido a Mujer & 0 & 0 & 6 & 9,7 & 0 & 0 & 0 & 0 & 6 & 5,4 \\
\hline Total H. No Forzosos & 2 & 0,8 & 62 & 96,9 & 12 & 66,7 & 36 & 90 & 112 & 29,3 \\
\hline Total & 260 & 100 & 64 & 100 & 18 & 100 & 40 & 100 & 382 & 100 \\
\hline
\end{tabular}

FUENTE: Testamentos. Protocolos Notariales. AHPL. Total casos: 382.

La designación de herederos fue uno de los aspectos más importantes a los que tenía que hacer frente una persona en sus últimos días de vida. Se observa como,

17.600 habitantes de los cuales el 70\% se dedican al sector primario. Censo de Floridablanca. 1787. Publicado por el Instituto Nacional de Estadística. Madrid, 1986.

17 Esto se hace así porque cada una de las actuaciones que realiza el Hombre deben de estar enmarcadas en un contexto que nos ayudará a explicar las diferentes estrategias que siguen dentro del proceso que estamos estudiando. 
siguiendo la legislación castellana ${ }^{18}$, al $70,7 \%$ de los testadores no les quedó otro recurso más que nombrar a los herederos legítimos (hijos y/o padres) ${ }^{19}$ y el resto $(29,32 \%)$ designó libremente los sucesores de su patrimonio. Dentro de los forzosos los hijos con un $97 \%$ de los casos se impondrán sobre los padres y dentro de los libremente designados los cónyuges con un $43 \%$ y los hermanos y sobrinos, con un $18 \%$ y $14 \%$ respectivamente, se alzan con los primeros puestos a la hora de heredar.

Pero estos resultados debemos analizarlos observando las diferentes situaciones en las que se producen, por lo que estos valores debemos precisarlos en cada uno de los grupos establecidos a tal afecto.

Comenzando el análisis por los matrimonios con hijos (con herederos legítimos) cabe destacar como a la muerte de uno de los cónyuges, en un 99,2\% dejan sus bienes a los hijos legítimos ${ }^{20}$, hijos póstumos y nietos del testador, es decir, a los herederos forzosos. En la zona de Valladolid ${ }^{21}$ el dato es del $85,5 \%$. Estos bienes son los que en la legislación castellana se conocen con el nombre de legitima, paterna y materna, que los padres se ven obligados a dar a sus hijos legítimos ${ }^{22}$. Además de poner de manifiesto que cada hijo tiene el derecho de recibir parte de la

${ }^{18}$ Lib. X, Tít. XX, Ley I (Ley 6 de Toro): Los ascendientes legítimos por su orden y línea derecha sucedan ex testamento y ab intestato a sus descendientes y les sean legítimos herederos como los son los descendientes a ellos en todos sus bienes cuales quiera que sean, en caso que los dichos descendientes no tengan hijos, en la Novísima Recopilación de la Leyes de España mandada formar por el señor D. Carlos IV, Madrid, 1805

19 También se incluyen los nietos cuyos padres hubiesen fallecido, ya que a éstos les corresponde la parte proporcional de la legitima de su difunto padre.

${ }^{20}$ Hijos legítimos de cualquier matrimonio que haya efectuado el testador a lo largo de su vida. Decimos esto porque las segundas y terceras nupcias eran bastante frecuentes, ya que, la mortalidad en estas sociedades era muy elevada (Provincia de León: 35-45\%), VV.AA. (RuBIO PÉREZ, L. Coord..). (1999). La Historia de León. Vol. Edad Moderna. Universidad de León, por lo que el número de hijos que habitaban bajo un mismo techo y que eran de diferentes padres, es bastante elevado.

${ }^{21}$ García Fernandez, M. (1995). Herencia y Patrimonio familiar en la Castilla.... Op. cit., pp. 186.

${ }^{22}$ Lib. X, Tít. XX, Ley I (Ley 6 de Toro): Los ascendientes legítimos por su orden y línea derecha sucedan ex testamento y ab intestato a sus descendientes y les sean legítimos herederos como los son los descendientes a ellos en todos sus bienes cuales quiera que sean, en caso que los dichos descendientes no tengan hijos, en la Novísima Recopilación de la Leyes ..., Op. cit. 
herencia de los padres, también se observa como el reparto debe de ser igualitario ${ }^{23}$ entre todos los hijos legítimos del testador y así aparece en los testamentos ${ }^{24}$.

Pero, a pesar de esta uniformidad aparente, se encierran algunas diferencias y consideraciones a tener en cuenta que serán muy importantes a la hora del computo final de la cuantía de la herencia. Así podemos observar que son herederos forzosos todos los hijos legítimos aunque sean de matrimonios diferentes, quedando fuera de dicha herencia los andados o hijastros que, aunque son hijos de la mujer / marido actual del testador, no lo son de la persona que realiza el testamento. Además suelen aparecer como herederos los nietos del testador cuando alguno de sus hijos ha fallecido, siguiendo las leyes vigentes y las costumbres de la zona ${ }^{25}$. Los nietos del testador y todos aquellos individuos que el hijo fallecido instituyó como beneficiarios recibirán, única y exclusivamente, la parte de la herencia que le correspondiese a dicho hijo fallecido. Estas tendencias nos reflejan dos aspectos contradictorios: por un lado, el peso que tenía la legislación sobre aquellas gentes $\mathrm{y}$, por otro, el intento de esos individuos por buscar unos mecanismos para burlar, en la medida de sus posibilidades, esa legislación. Así las mandas testamentarias y las mejoras post mortem se convertirán en fundamentales para tal fin, otorgando primacía a unos hijos sobre otros. Este igualitarismo encubierto se lleva hasta su extremo cuando se instituyen como herederos a los hijos póstumos que nacerán una vez fallecido el testador. Si estos muriesen al nacer se dan dos soluciones que se enmarcan dentro de este proceso:

1. cuando el hijo póstumo es el único vástago, entonces si este muere los bienes son incorporados al patrimonio de la mujer/marido del testador, pasando así a la

${ }^{23}$ En la vega Baja del Esla también se impone este reparto igualitario entre los hijos legítimos del testador como nos lo presenta PÉREZ GARCíA, J. M. (1998). Un modelo social leonés en crecimiento: la Vega Baja del Esla entre 1700-1850. León. Lo mismo ocurre en la zona Vallisoletana donde los hijos legítimos también eran los herederos. Vid. García Fernandez, M. (1995). Herencia y patrimonio familiar en la Castilla del Antiguo Régimen (1650-1834). Efectos socioeconómicos de la muerte y la partición de bienes. Universidad de Valladolid. Pp. 27. Aunque este sistema igualitario no está generalizado por todo el territorio leonés, como se pone de manifiesto en la Maragatería, véase RuBio PÉREZ, L. (1995). La burguesía Maragarata. Universidad de León.

${ }^{24}$ Por ejemplo:...mando se repartan por iguales entre mis hijos Tomas, Anastasia, Cecilia y Luisa Fernández... AHPL, José Antonio García Siero, Caja 4524.

25 ... únicos y universales herederos a Santos y Martina Carvajal mis hijos y a los herederos e hijos de Miguel, Benito, Bárbara, Lupercia y María mis hijos difuntos..., AHPL, José Antonio García Siero, Caja 4528. 
categoría que hemos establecido denominada matrimonio sin hijos donde, como veremos, la primacía sobre la herencia de los bienes la tiene el otro cónyuge ${ }^{26}$.

2. cuando el hijo póstumo no es el único vástago entonces éste es nombrado como heredero pero si muere su parte de la herencia iría a parar a los demás hermanos.

Como se observa, siempre se siguen unos patrones: si hay hijos, éstos son los herederos y si no los hay, bien por muerte o porque no ha habido descendencia, entonces es uno de los cónyuges.

Cuadro 2: $N^{o}$ hijos por familia que hace testamento. 1700-1820.

\begin{tabular}{cccc}
\hline Hijos herederos & $N^{o}$ casos & $\%$ & Total hijos \\
\hline 0 & 88 & 25 & 0 \\
1 & 50 & 14,20 & 50 \\
2 & 68 & 19,32 & 136 \\
3 & 56 & 15,91 & 168 \\
4 & 34 & 9,66 & 136 \\
5 & 30 & 8,52 & 150 \\
6 & 12 & 3,41 & 72 \\
7 & 12 & 3,41 & 84 \\
8 & 2 & 0,57 & 16 \\
\hline Total & 352 & 100 & 812 \\
\hline Solteros & 30 & 7,85 & \\
\hline Total & 382 & \\
\hline Media hijos por matrimonio & \multicolumn{3}{l}{} \\
\hline
\end{tabular}

FUENTE: Testamentos. Protocolos Notariales (Sahagún). AHPL. Total Casos: 382.

Como podemos ver en el cuadro, una cuarta parte de los casos analizados no tienen hijos ${ }^{27}$ cuando realizan el testamento por lo que se produce una designación libre de herederos. Valores similares se dan en otras zonas limítrofes como la vega

${ }^{26}$ Por ejemplo: ... al póstumo a póstuma que diese a luz $D^{a}$ Rosa Morgrobejo y si no esta preñada dejo mis bienes a $D^{a}$ Rosa Morgrobejo, mi mujer por los días de su vida. Después nombro por heredera a Clara de Prado mi sobrina...., AHPL, Manuel Martínez, Caja 4531.

${ }^{27}$ Este dato se corrobora con el cuadro 1 donde se muestra el elevado porcentaje de testamentos cuyos cónyuges no tiene hijos vivos cuando lo realizan (17\%). 
del Esla ${ }^{28}$ con un $24,81 \%$ de casos. Destacan los matrimonios de uno a tres hijos que acumulan casi el $50 \%$ de los casos, por lo que el número medio por matrimonio ronda los 2,3 hijos ambos valores similares a la Vega del Esla que son de 2,19 hijos por matrimonio ${ }^{29}$. Por otro lado, el número de las familias con $5 \mathrm{o}$ más hijos es elevado con casi un 16\% del total, algo inferior que en la vega del Esla que es del 14,89\%. Todos estos datos referentes al número medio de hijos, al elevado porcentaje de matrimonios sin hijos, etc., serán de gran ayuda a la hora de comprender las diferentes estrategias hereditarias llevadas a cabo por estas familias.

Otro grupo es el de los matrimonios sin hijos vivos cuyos herederos forzosos serán los padres (Cuadro 1). Para este grupo en el 3\% de los casos, tendrían un heredero forzoso que sería el padre y el resto $(97 \%)$ podría repartirlo libremente entre las personas que estimase más oportuno ${ }^{30}$. Dentro de éstos el escogido sería el cónyuge que ha quedado vivo en más de un $84 \%$. En los casos donde el predominio del cónyuge es abrumador, el resto de la familia del testador quedaría reflejada de forma testimonial en las mandas testamentarias ${ }^{31}$ donde recibirá algún tipo de bien. Después son los sobrinos del testador, con un $9 \%$, los que tengan parte de la herencia de algunos de sus tíos. Este hecho tiene grandes consecuencias para las familias porque, los bienes del testador se incorporan al patrimonio del otro cónyuge, con la posibilidad de que éste contraiga matrimonio con otra persona y a su vez tenga hijos, por lo que parte de los bienes del fallecido pasarían a unos hijos que no son legítimos de éste, provocando una dispersión patrimonial. Este hecho se intenta remediar mediante la utilización de las mandas testamentarias donde el testador, deja a hermanos y sobrinos (personas de la misma línea familiar) gran cantidad de bienes o poniendo algún tipo de cláusula o condición al cónyuge heredero para que a su muerte los bienes regresen al tronco familiar de donde han

${ }^{28}$ PéRez García, J. M. (1998). Un modelo social leonés.., Op. cit., pp. 104.

${ }^{29}$ Estas medias se sitúan muy cercanas a las que se producen en otras zonas leonesas como entre los campesinos y jornaleros maragatos que se sitúan en 2,27 hijos Vid. RUBIO PÉREZ, L. (1995). La burguesía Maragarata..., Op. cit., p. 146. Todas las cifras dadas hasta ahora son inferiores a las que se producen en la Huerta Valenciana que llega a los 3,91 hijos por matrimonio. Vid. PÉrez GarcíA, J.M. (1988). «La familia campesina en la Huerta de Valencia durante el siglo XVIII». Boletín A.D.E.H., Vol. IX, n ${ }^{\circ} 2$.

${ }^{30}$ Serán las personas que pertenecen a este grupo las que pueden repartir sus patrimonios entre un número más variado de individuos.

31 “... instituyo como heredera a Eugenia Ampudia mi mujer porque no tengo herederos forzosos... (aquí los herederos forzosos serían los hijos según las leyes castellanas). AHPL, Manuel Cañibano, Caja 4587. 
salido. Ésto es una clara expresión del intento por conservar los patrimonios heredados de los padres, aunque a veces es más fuerte el cariño que se profesa a una persona ${ }^{32}$ que cualquier otro aspecto económico, y así los bienes pasarían íntegros para el cónyuge vivo sin ningún tipo de medida correctora.

Cuadro 3. Estado civil del cónyuge heredero en el grupo casado sin hijos. 1700-1820.

\begin{tabular}{|c|c|c|c|c|c|c|}
\hline \multirow{3}{*}{ Estado Civil } & \multicolumn{6}{|c|}{ Beneficiarios } \\
\hline & \multicolumn{2}{|c|}{ Marido } & \multicolumn{2}{|c|}{ Mujer } & \multicolumn{2}{|c|}{ Total } \\
\hline & $N^{o}$ & $\%$ & $N^{o}$ & $\%$ & $N^{o}$ & $\%$ \\
\hline Casado $1^{a}$ Nupcias & 12 & 62,5 & 22 & 84,6 & 34 & 73,9 \\
\hline Casado $2^{\mathrm{a}}$ Nupcias & 8 & 37,5 & 4 & 15,4 & 12 & 26,1 \\
\hline Total & 20 & & 26 & & 46 & 100 \\
\hline
\end{tabular}

FUENTE: Testamentos. Protocolos Notariales. AHPL.

Adentrándonos más en este grupo, cabe mencionar que el número de matrimonios en primeras nupcias $(73,9 \%)$ en los que el beneficiario es el otro cónyuge es muy superior al número donde lo es en segundas nupcias $(26,1 \%)$ y por sexos llega a superar el $84,6 \%$ para las mujeres y el $62,5 \%$ para los hombres, por lo que hay un número mayor de mujeres beneficiarias de los patrimonios de sus maridos. Aunque, en los matrimonios casados en $2^{\mathrm{a}}$ nupcias, la diferencia entre sexos es mucho más atenuada entre los varones que entre las mujeres ${ }^{33}$. Dentro de los matrimonios en $1^{\text {a }}$ nupcias la mujer es nombrada con heredera en un $64,7 \%$ de los casos, muy superior que en el caso del hombre. En los matrimonios en $2^{\mathrm{a}}$ nupcias se produce un cambio en los datos, pasando a ser el marido el principal heredero con un $66,7 \%$. Se observa como, dependiendo del estado civil en el que se encuentre el testador, la inclinación hacia un uno u otro cónyuge es muy notable.

Pero a pesar de todo, a falta de heredero forzoso, el usufructuario de los bienes siempre será el cónyuge (marido o mujer indistintamente) pertenezca al matrimonio que pertenezca. Por otro lado, se pone de manifiesto que cuando el

${ }^{32}$ A partir de mediados del siglo XX se produce un interés por este tipo de estudios vinculados a la cotidianeidad como el trabajo de ARÍES, Ph. (1960). L'enfant et la vie familiale sous l'ancien Régime pionero en tratar temas referentes a la socialización y a los aspectos sentimentales de la familia. Más recientemente el trabajo de ANTÓn PELAYO, J. (1998). «Comportamientos familiares y actitudes culturales durante la época moderna». Studia Historica. Salamanca. Pp. 67-101, donde pone de manifiesto la progresiva importancia de los sentimientos en la conformación de los matrimonios modernos.

${ }^{33}$ Entre los varones la diferencia entre casado en $1^{\mathrm{a}}$ y $2^{\mathrm{a}}$ nupcias es del $25 \%$ más y entre las mujeres asciende a más del $69 \%$ de diferencia entre una situación y otra. 
individuo sale de la casa paterna para constituir una nueva unidad familiar, los vínculos de unión con hermanos y padres se van perdiendo progresivamente, siendo el/la nuevo/a compañero/a el que comience a estrechar unos vínculos que se van haciendo más fuertes llegando a preferir a la hora de testar al cónyuge sobre el resto de miembros de su familia. Esto se produce, principalmente, cuando la heredera es la mujer, ya que a la muerte del marido era normal que la viuda pasara por un periodo de estrechez económica que el marido quería paliar instituyéndola como única heredera. En muchas ocasiones para evitar que un futuro matrimonio de la viuda provocase la huida de los bienes hacia un nuevo núcleo familiar, el marido solía dejarla como usufructuaria (por los días de su vida), por lo que a su muerte el patrimonio volvería a la familia del testador, sobrinos o hermanos ${ }^{34}$ o por otro era invertido en misas por el alma de ambos esposos ${ }^{35}$.

Dentro del grupo de los solteros (Cuadro 1) el 10\% de los testadores deja como herederos forzosos a los padres y el resto $(90 \%)$ los designarán libremente. Entre éstos destacan como principales beneficiarios los hermanos del testador, con un $50 \%$ sobre otros familiares más cercanos como sobrinos o primos, con un $11 \%$. Destaca con el 16\% la designación como heredero de un ente no físico (el alma) ${ }^{36}$, cuya importancia económica es muy grande para las instituciones eclesiásticas que se encargarán de gestionar y administrar esos caudales. Esto también nos indica desde el punto de vista de las mentalidades, una expresión del sentir popular y la religiosidad de las gentes del siglo XVIII y que demuestra que por encima de cualquier beneficio económico y personal está el beneficio espiritual.

34 ... instituyo como heredero a Juan Antón mi marido por el tiempo y días de su vida y después vuelva a mis sobrinas y de mi marido hijas de Antonio Villalobos y María Antón... Se observa como son las sobrinos/as de la familia de la testadora no a los sobrinos/as del marido. De este modo, los bienes al final de la vida del cónyuge volverán a la familia de donde habían partido. AHPL, José Antonio García Siero, Caja 4529.

35 “

“...Mando que una vez muerto mi marido los bienes se inviertan en sufragios por su ánima y la mia y en indulgencias...” AHPL, Juan Felipe y Godos, Caja 4470.

${ }^{36}$ Así aparecen expresiones como... dejo como única y universal heredera a mi alma y al de mis padres... entendiendo tal hecho como una forma de redimir los pecados, ya que, queda asentado que... se gaste en misas y sufragios... AHPL, Antonio Mata, Caja 4347.

... que los bienes se vendan y digan misas... AHPL, Caja 4588. 
La" mejora"como una froma de corregir el igualitarismo castellano. Comarca de Sahún, siglo XVIII

Cuadro 4: Número de hermanos herederos en el grupo solteros. 1700-1820.

\begin{tabular}{lrrr}
\hline & $N^{o}$ de herederos & $N^{o}$ & $\%$ \\
\hline Algunos hermanos & 10 & 55,6 \\
Todos los Hermanos & 8 & 44,4 \\
\hline Total & 18 & 100 \\
\hline
\end{tabular}

FUENTE: Testamentos. Protocolos Notariales. AHPL.

En algo más del 55\% de los casos son instituidos como herederos algunos de los hermanos, que bien por motivaciones de tipo sentimental o por actuaciones que tienen una determinada intencionalidad, constituyen una táctica para intentar mejorar a unos hermanos en detrimento de los otros, aunque puede ser visto como una forma de reequilibrar las herencias recibidas de sus padres u otros familiares o para el pago de aspectos determinados como estudios, dotes de religiosos, etc., constituyendo un elemento importante para el incremento de los bienes patrimoniales de los individuos que se vienen a sumar a las legitimas paterna y materna.

Por último, en el grupo de los viudos (Cuadro 1) el 33,3\% de los testadores tiene que nombrar herederos forzosos (hijos) y el resto (más del 66\%) son de libre designación. Entre éstos destacan los sobrinos con un 50\%. Muy por debajo se encuentran los hermanos con un $16 \%$. Fuera del tronco familiar se sitúan los vecinos con un 33\% de los casos colocándose en segundo lugar y doblando a otros como los hermanos ${ }^{37}$. Esta actuación provoca que el patrimonio salga fuera del tronco familiar, pero, por otro lado, crea una red clientelar y vecinal que supera el propio ámbito familiar. A pesar de ello, el difunto intenta que el grueso patrimonial (legitimas heredadas de sus padres) se quede en su familia, por lo que serán los bienes conseguidos a lo largo de su vida, los que vayan a parar fuera del núcleo familiar $^{38}$. Esto puede ser interpretado como una forma de premiar a ciertos individuos ajenos al núcleo familiar que se merecen algún tipo de contrapartida económica por algún servicio prestado, dando origen a todo un entramado de solidaridades vecinales que van más allá de la propia familia y que constituyen la base de aquellas sociedades.

En conclusión, se observa a grandes rasgos tres hechos:

37 ... instituyo como heredero a Juan y Bernarda Alonso vecinos de San Pedro de Valderaduey..., AHPL, Jacinto Villanueva, Caja 4391.

38 ... mando a María Testera y Manuel Testera mis sobrinos la heredad y casa que me correspondió por legitima de mis padres y que la partan con igualdad..., AHPL, José Antonio García Siero, Caja 4527. 
1. Cuando hay herederos legítimos (hijos/nietos y padres), éstos son instituidos como tales siguiendo la tradición legislativa castellana.

2. Cuando no hay herederos legítimos, será el otro cónyuge el que se hace con los bienes del testador en un intento de rehacer su vida o, por lo menos, acabar ésta de la forma más digna posible.

3. Cuando no hay herederos legítimos ni cónyuge, es decir, son individuos solteros, entonces serán los hermanos y sobrinos del testador quienes son instituidos como herederos con el objetivo de que los bienes permanezcan en el núcleo familiar.

\section{LA 'MEJORA' POST MORTEM ${ }^{39}$ : UNA FORMA DE ROMPER EL IGUALITARISMO.}

Como hemos dicho, existe una cantidad de bienes que debían recibir por igual todos los descendientes del difunto y es lo que se denomina "legitima". Pero los padres tenían a su disposición una porción del patrimonio para repartirlo entre quienes ellos desearán, que se denomina, 'mejora' y que constituía otra formula, además de las mandas testamentarias, los legados, donaciones, etc., para dejar diversos bienes a las personas que ellos estipulasen. Hasta el momento hemos visto qué personas eran instituidas como herederas, pero existen mecanismos para modificar la dirección de esa herencia que, según las leyes castellanas, iría orientada a un reparto igualitario. Estos métodos que distorsionan el igualitarismo están puestos a disposición del individuo para que les utilice de una u otra forma para conseguir su objetivo, dando origen a una estrategia familiar determinada que trataremos de analizar en este apartado.

Algunos de estos mecanismos correctores del igualitarismo son las mandas testamentarias $^{40}$, instrumento donde el testador deja reflejado los aspectos relacionados con el destino de algunos de los bienes materiales, y la mejora post mortem en la cual se basará nuestro análisis.

${ }^{39}$ La mejora post mortem es la practica legal de segregación de una parte de los bienes a favor de uno de los hijos que es añadida a su legítima. Se suele establecer en vida de los padres para ser entregada después de su muerte. Como veremos más adelante además de los hijos es entregada al cónyuge, nieto, etc. EIRAS Roel, A. Tipología documental de los Protocolos gallegos. Santiago de Compostela.

${ }^{40}$ Sexta Partida, Título IX Ley I. Manda es una manera de donación que deja un hombre en el testamento. Puede hacer la manda todo hombre que puede hacer testamento. Siete Partidas del sabio rey Don Alfonso..., Op. cit. 
Cuadro 5. Estrategias sucesorias. 1700-1800.

\begin{tabular}{lrr}
\hline \multicolumn{1}{c}{ Tipo de herencia } & $N^{\circ}$ Casos & $\%$ \\
\hline Reparto igualitario & 150 & 39,3 \\
Mejora $1 / 3$ y $1 / 5$ & 30 & 7,9 \\
Mejora $1 / 3$ & 10 & 2,6 \\
Mejora $1 / 5$ & 26 & 6,8 \\
Hedero único & 50 & 13 \\
Hedero de soltero y casado/viudo sin hijos & 116 & 30,4 \\
\hline Total & 382 & 100,0 \\
\hline
\end{tabular}

FUENTE: Testamentos y escrituras de mejora. Protocolos Notariales. AHPL.

En los datos que nos ofrece el Cuadro 5 podemos apreciar como se impone el reparto igualitario con un $39,3 \%$, frente a las mejoras $(17,28 \%)$ y dentro de éstas serán las mejoras conjuntas de $1 / 3$ y $1 / 5$ con un $7,85 \%$ las que más abundan seguidas de cerca por las mejoras de $1 / 5$ con un $6,81 \%$. Destaca la existencia del heredero único ${ }^{41}$ con un $13 \%$. Pero lo que realmente sobresale, y lo podemos poner en relación con la escasez del predominio del reparto igualitario, es el elevado porcentaje de solteros y personas sin hijos que constituyen casi un tercio del total, como ya analizamos en el Cuadro 2. Destaca que el $70 \%$ de los matrimonios tenían hijos vivos a la muerte de uno de los progenitores, dato éste que baja al $50 \%$ en la zona vallisoletana, por lo que estas personas quedaban exentas de regularse por el reparto igualitario y podían dejar su hacienda a la/s persona/s que estimasen oportuno en cada momento, dependiendo de la estrategia a seguir con el resto de sus parientes.

Estos datos podemos compararlos con dos zonas limítrofes ${ }^{42}$ : Vega del Esla y zona castellana de Tierra de Campos (Valladolid y alrededores). En relación con la zona de la Vega de Esla ${ }^{43}$ aunque el número de mejoras es bastante menor (10\%) sigue la misma tendencia de predominio del tercio y del quinto en una misma

${ }^{41}$ Entendiendo como tal aquellos matrimonios que instituyen como heredero a un hijo debido a que solo han concebido uno.

${ }^{42}$ Vamos a comparar las dos zonas más importantes que limitan con nuestra zona de estudio. La primera zona con unas características especificas lo constituye la vega del río Esla en contraposición de la Tierra de Campos castellana seca y cerealera quedando en medio nuestra zona de estudio que pasa a ser una comarca de transición entre una y otra reuniendo en ella los aspectos de las anteriores que más provecho la reporten en relación con las condiciones sociales, económicas, demográficas, etc. que la caracterizan, y que en éste y otros trabajos vamos a analizar.

${ }^{43}$ Pérez García, J. M. (1998). Un modelo social leonés..., Op. cit., pp. 104. 
mejora. Lo mismo ocurre con el porcentaje asignado al reparto igualitário, que es algún punto inferior, y el correspondiente al heredero único se mueve por los mismos parámetros. Es sobresaliente también el elevado porcentaje de solteros y matrimonios sin hijos, aunque siempre inferior que en Tierra de Campos Leonesa ${ }^{44}$, por lo que, en esta zona, el grupo que no tiene hijos (herederos forzosos) pasará a jugar un papel muy importante en la distribución del patrimonio mueble y raíz, y favorecerá la aparición multitud de estrategias y clientelismos dentro y fuera de la propia familia. En la zona castellana (Valladolid y alrededores) la práctica de mejorar respecto con la del reparto igualitario es del 15\% acercándose más a los valores de la comarca de Sahagún, aunque siempre inferior a ésta. Así nuestra zona con más de un $17 \%$ se alza con el primer puesto a la hora de realizar este tipo de tácticas hereditarias. Pero la escasez de mejoras puede ser debida, no solo al cumplimiento estricto del derecho, sino a la imposibilidad de mejorar de las familias, ya que era necesario un mínimo de bienes y unas personas cercanas a las que legarlos ${ }^{45}$, que por alguna razón necesitasen esos bienes o formasen parte de una estrategia organizada por los progenitores para asegurar el desarrollo familiar. Por lo tanto, nuestro modelo está representado mayoritariamente por el reparto igualitario contraponiéndose a zonas de España como la Huerta Valenciana ${ }^{46}$, la Galicia Occidental e interior, donde la desigualdad se acentúa mucho más ${ }^{47}$, y el caserío vasco donde abundan las mejoras y el reparto igualitario es escaso ${ }^{48}$.

${ }^{44}$ Otros modelos hereditarios de algunas de las zonas más representativas de León son: en la zona del Bierzo donde predomina el reparto igualitario con un $62 \%$, seguido de herederos únicos (por no tener más) con un $17 \%$ y las personas que no tiene hijos y solteros con un $21 \%$. Vid. BARTOLOMÉ BARtolomé, J.M. (1996). Vino y viticultores en el Bierzo. Sociedad y estructuras económicas durante el siglo XVIII. Universidad de León. p. 342. Otro es el modelo maragato estudiado por el profesor RUBIO PÉREZ, L. (1995). La burguesía Maragata. Universidad de León. pp. 146-164, donde las mejoras a favor de los hijos son muy abundantes al igual de lo que ocurría en la montaña leonesa. Vid. Pérez Álvarez, M.J. (1994). La montaña noroccidental leonesa durante la Edad Moderna. Hombres, Concejos y estructuras socioeconómicas en una sociedad tradicional. Universidad de León. pp. 766-769 y 803-805.

45 García Fernández, M. (1995). Herencia y patrimonio familiar en la Castilla..., Op. cit., p. 168.

${ }^{46}$ Vid. GARRIDO ARCE, E. (1992). «La imposible igualdad. Familia y estrategias hereditarias en la Huerta Valenciana a mediados del siglo XVIII». Boletín A.D.E.H., n 3, pp. 94-102.

47 Vid. Fernández CoRTizo, C. (1989). «En casa y compañía: grupo domestico y estrategias familiares en la Galicia Occidental a mediados del siglo XVIII», en Parentesco, Familia y matrimonio en la Historia de Galicia. Univ. de Santiago. pp. 158-160.

48 Urriticoechea lizarraga, J. (1992). En una misma casa y compañia. Caserio y familia campesina en la crisis de la sociedad tradicional. Irún, 1766-1845. Univ. Deusto. p. 242. También ver Arbaiza Villallonga, M. (1996). Familia, Trabajo y Reproducción Social. Una perspectiva 


\section{LA 'MEJORA' POST MORTEM: UNA MANDA TESTAMENTARIA ESPECIAL.}

Dentro de las mandas testamentarias destacan lo que conocemos como mejoras del quinto y tercio o, como normalmente se conoce, el quinto de libre disposición y el tercio de mejora, figuras jurídicas que van encaminadas a distorsionar el igualitarismo del derecho castellano. Estos recursos permitían incrementar la legítima paterna o materna ${ }^{49}$, en muchos casos, de forma sustancial ${ }^{50}$. Este hecho nos muestra claramente que el igualitarismo no se llega a conseguir ${ }^{51}$ en estas tierras en el siglo XVIII, siendo una practica habitual y legal la segregación de una parte de los bienes en favor de una/s persona $/ \mathrm{s}^{52}$. Aunque, como más adelante veremos, los motivos que subyacen con cada una de las mejoras que se llevan a cabo pueden ser muy diversos, aunque, normalmente, es para que el hijo/a viva en casa con sus padres y cuide de ellos en su vejez ${ }^{53}$, convirtiéndose en un seguro asistencial, o para resarcir los gastos ocasionados por los padres en el transcurso de su ancianidad al cuidado del hijo mejorado. Así, aunque es una ruptura con el igualitarismo, muchas veces lo que nos está indicando es un reajuste de las herencias equilibrando el patrimonio de cada heredero o dando a cada uno aquellos bienes de los que más provecho pueda sacar, dependiendo de su ocupación profesional o de la condición social que ostente.

microhistórica de la sociedad vizcaina a finales del Antiguo Régimen. Univ. del País Vasco. Bilbao. pp. 95-114.

49

... mando por ley de mejora a mi hijo Agustín García el tercio de mis bienes además de lo que le toca por herencia..., AHPL, José Antonio García Siero, Caja 4524.

${ }^{50}$ García GonZalez, F. (2001). Las estrategias de la diferencia. Familia y Reproducción Social en la Sierra. (Alcaraz, siglo XVIII). Madrid.

${ }^{51}$ Véase también, LorEnzo PINAR, F.J. (1991). «La familia y la herencia en la Edad Moderna Zamorana a través de los testamentos». Studia Historica, Vol. IX, pp. 159-201. No se concibe como un reparto equitativo sino como un incremento de patrimonio dependiendo de las necesidades de cada beneficiario.

52 Pero con el paso del tiempo el uso y abuso de este tipo de mandas especiales hizo que la legislación castellana comenzara a legislar contra su uso para evitar que se desvirtuara la esencia del reparto igualitario. Lib. X, Tít. VI, Ley X (Ley 26 de Toro): La donación hecha al hijo se entiende mejora, en lo que cupiese del tercio y quinto y legitima. Se hace para que ninguno pueda ser mejorado en más de ese tercio y quinto de los bienes. Novísima Recopilación de la Leyes ..., Op. cit.

${ }^{53}$ Eiras Roel, A. Tipología documental de los Protocolos gallegos. Santiago de Compostela, 
El sistema de mejora explica la autoridad paterna reforzando la unidad familiar alrededor de la casa ${ }^{54}$ y la autoridad del heredero permitiendo el reparto desigual del patrimonio familiar entre el resto de los descendientes ${ }^{55}$. De este modo, las mejoras tienen como objetivo el control familiar mediante la aplicación de una estrategia determinada que irá encaminada, por una parte, a la reproducción del sistema $^{56} \mathrm{y}$, por otra, a ser una salvaguarda en los últimos días de vida de los testadores.

Una vez llegado a este punto, debemos conocer las personas que se benefician de la mejora y la cuantía de la misma. Es importante resaltar que al poner en relación el/los heredero/s del testamento con la persona que recibe la mejora, podemos observar que solo aparecen mejoras testamentarias cuando los herederos del testamento son el/los hijo/s o nietos (herederos forzosos) que es cuando se produce el reparto igualitario y, por lo tanto, la posibilidad de poder romper con ese igualitarismo mediante la utilización de esta herramienta ${ }^{57}$.

En esta zona encontramos que solo hay mejoras cuando los testadores tienen herederos forzosos, hijos y nietos, ya que existiendo éstos los progenitores solo podían beneficiar a otras personas mediante mandas testamentarias o donaciones, siempre en menos de la quinta parte de sus bienes. Como podemos ver en el Cuadro $6 \mathrm{a}$, más del $60 \%$ de las mejoras realizadas tienen por beneficiario el/los hijo/s del testador seguido de lejos por el cónyuge vivo con un $31,8 \%$, lo que nos hace pensar en una forma de estrategia a seguir entre los miembros de dichas familias en la que prima el mantenimiento del patrimonio dentro del tronco familiar. También puede ser una expresión del agradecimiento por los servicios prestados al cónyuge enfermo o impedido. Así, en un 92,4\%, son hijos y cónyuges los que se llevan las mejoras que se realizan en la zona, por lo tanto, se intuye que el testador quiere dejar sus bienes a las personas cercanas con las que ha

${ }^{54}$ La casa pasa a ser el elemento de unión entre los distintas miembros de la familia y las diferentes tendencias y sensibilidades que afectaban a éstos y que se llevaban a cabo entre sus paredes.

55 García Fernández, M. (1995). Herencia y patrimonio familiar en la Castilla..., Op. cit. p. 167.

${ }^{56} \mathrm{La}$ idea de reproducción social se encuentra con un problema añadido: todos los hijos tienen que reproducirse socialmente. Pero si los medios materiales permitían a una familia un determinado status social, la dificultad surge cuando hay que conseguir una familia con los mismos medios materiales que la familia inicial para todos los hijos. Así las estrategias familiares tendrán que solventar ese problema. FerRer I Alos, LL. (1995). Notas sobre el uso de la familia..., Op. cit., p. 18.

${ }^{57}$ Es por este motivo, por el cual, no se han podido elaborar cuadros para estudiar la aparición de mejoras cuando el heredero es una persona diferente al/los hijo/s del difunto. 
compartido su vida y le han ayudado, con su trabajo y sus bienes aportados al matrimonio, a aumentar el patrimonio familiar, e impidiendo posibles perdidas patrimoniales y así concentrar en los familiares más cercanos todos los bienes constituyendo un núcleo más fuerte desde el punto de vista patrimonial. Estos datos son algo diferentes de los que se producen en la zona castellana de Valladolid y alrededores donde el número de mejoras realizadas a los hijos es algo inferior situándose en $51,36 \% \mathrm{y}$, por el contrario, la que realizan a los cónyuges es superior con un $41,83 \%$, aunque el conjunto de ambos supera el $92 \%$ del total, cifra similar a lo que se produce en nuestra zona de estudio ${ }^{58}$.

Cuadro 6a: Individuos mejorados en los testamentos. 1700-1820.

\begin{tabular}{lcccccccccccc}
\hline & \multicolumn{10}{c}{ Individuo Mejorado } \\
\cline { 2 - 14 } Mejora & \multicolumn{1}{c}{ Cónyuge } & \multicolumn{1}{c}{ Un hijo } & \multicolumn{1}{c}{ Varios hijos } & \multicolumn{1}{c}{ Yerno } & Nieto & \multicolumn{2}{c}{ Total } \\
\cline { 2 - 14 } & $N^{o}$ & $\%$ & $N^{o}$ & $\%$ & $N^{o}$ & $\%$ & $N^{o}$ & $\%$ & $N^{o}$ & $\%$ & $\mathrm{~N}^{\circ}$ & $\%$ \\
\hline Quinto & 21 & 100 & 2 & 6,1 & 3 & 42,9 & 0 & 0 & 0 & 0 & 26 & 39,4 \\
Tercio & 0 & 0 & 7 & 21,2 & 0 & 0 & 0 & 0 & 3 & 100 & 10 & 15,2 \\
Ambas & 0 & 0 & 24 & 72,7 & 4 & 57,1 & 2 & 100 & 0 & 0 & 30 & 45,5 \\
\hline Total & 21 & 100,0 & 33 & 100,0 & 7 & 100,0 & 2 & 100,0 & 3 & 100,0 & 66 & 100,0 \\
\hline
\end{tabular}

FUENTE: Testamentos y escrituras de mejora. Protocolos Notariales. AHPL.

Cuadro 6b: Porcentaje del tipo de mejora que se realiza a los indivuduos. 1700-1820.

\begin{tabular}{lcccccc}
\hline & \multicolumn{6}{c}{ Mejora que se realiza } \\
\cline { 2 - 7 } \multicolumn{1}{c}{ Individuo mejorado } & \multicolumn{2}{c}{ Quinto } & \multicolumn{3}{c}{ Tercio } & \multicolumn{3}{c}{ Ambas } \\
\cline { 2 - 7 } \multicolumn{1}{c}{$N^{o}$} & $\%$ & $N^{o}$ & $\%$ & $N^{o}$ & $\%$ \\
\hline Cónyuge & 21 & 80,8 & 0 & 0 & 0 & 0 \\
Un hijo & 2 & 7,7 & 7 & 70 & 24 & 80,0 \\
Varios hijos & 3 & 11,5 & 0 & 4 & 4 & 13,3 \\
Yerno & 0 & 0 & 0 & 0 & 2 & 6,7 \\
Nieto & 0 & 0 & 3 & 30 & 0 & 0,0 \\
\hline Total & 26 & 100 & 10 & 100 & 30 & 100,0 \\
\hline
\end{tabular}

FUENTE: Testamentos y escrituras de mejora. Protocolos Notariales. AHPL.

${ }^{58}$ Aunque en conjunto el número de mejoras realizadas a las personas más cercanas al testador (hijos y cónyuge) es el mismo (92\%), el reparto de éstas es diferente, pero a pesar de todo, la tendencia a lo largo del siglo va a ser la misma que la que se produce en la comarca de Sahagún. GARCía FernándeZ, M. (1995). Herencia y patrimonio familiar en la Castilla..., Op. cit., pp. 170-173 
Uno de los aspectos importantes que nos ofrece el Cuadro 6bes la diferente asignación en la cantidad de la mejora dependiendo del individuo mejorado. Dentro de cada grupo, el cónyuge solo es mejorado con el quinto mientras que el/los hijo/s son mejorados con tercio y quinto a la vez, aumentando el porcentaje de mejoras del quinto cuando son varios hijos los beneficiarios. El quinto o el remanente del quinto es asignado en el $80 \%$ de los casos al cónyuge que ha quedado vivo como una pequeña compensación por todos los años que han compartido juntos ${ }^{59}$. Este tipo de mejora pasa a ser menos relevante $(7 \%$ y $11,5 \%)$ entre los hijos del testador. La mejora del tercio y la del tercio y quinto aparece mayoritariamente cuando el beneficiario es uno de los hijos ( $70 \%$ y $80 \%$ respectivamente) descendiendo ésta al 4\% y $13 \%$ cuando los beneficiarios son varios hijos. Este hecho nos indica que los testadores prefieren mejorar con una cantidad mayor de bienes a alguno de sus hijos o nietos como una forma de perpetuación del patrimonio dentro del tronco de procedencia, ya que mejorando al cónyuge cabría la posibilidad de un segundo matrimonio con la consiguiente perdida del parte de los bienes.

Fuera de la línea de descendientes directos están los nietos $(4,55 \%)^{60}$ a los que se mejorará con el tercio y al yerno $(3 \%)$ que lo harán con ambas a la vez.

Cuadro 7: Individuos mejorados por sexos. 1700-1800

\begin{tabular}{|c|c|c|c|c|c|c|c|c|c|c|c|c|c|c|}
\hline \multirow[b]{3}{*}{ Mejora } & \multicolumn{6}{|c|}{$1700 / 1749$} & \multicolumn{6}{|c|}{$1750 / 1800$} & \multirow{2}{*}{\multicolumn{2}{|c|}{ Total }} \\
\hline & \multicolumn{2}{|c|}{ Hombre } & \multicolumn{2}{|c|}{ Mujer } & \multicolumn{2}{|c|}{ Total } & \multicolumn{2}{|c|}{ Hombre } & \multicolumn{2}{|c|}{ Mujer } & \multicolumn{2}{|c|}{ Total } & & \\
\hline & $N^{o}$ & $\%$ & $N^{o}$ & $\%$ & $N^{o}$ & $\%$ & $N^{o}$ & $\%$ & $N^{o}$ & $\%$ & $N^{o}$ & $\%$ & $N^{o}$ & $\%$ \\
\hline $1 / 3$ y $1 / 5$ & 2 & 10 & 18 & 90 & 20 & 47,6 & 12 & 54,5 & 10 & 45,5 & 22 & 52,4 & 42 & 51,2 \\
\hline $1 / 3$ & 2 & 50 & 2 & 50 & 4 & 40 & 2 & 33,3 & 4 & 66,7 & 6 & 60 & 10 & 12,2 \\
\hline $1 / 5$ & 8 & 50 & 8 & 50 & 16 & 53,3 & 10 & 71,4 & 4 & 28,6 & 14 & 46,7 & 30 & 36,6 \\
\hline Total & 12 & 30 & 28 & 70 & 40 & 48,8 & 24 & 57,1 & 18 & 42,9 & 42 & 51,2 & 82 & 100,0 \\
\hline
\end{tabular}

FUENTE: Protocolos Notariales (Sahagún). AHPL.

Según el Cuadro 7, en la primera mitad del siglo XVIII hay un predominio de las mejoras realizadas a las mujeres frente a las realizadas a los hombres, un $70 \%$

\footnotetext{
${ }^{59}$ Muchas veces, cuando se quería recompensar la atención prestada al cónyuge no se podía hacer porque la ley decía que la herencia debía de recaer en los descendientes, salvo los porcentajes reservados a libre disposición, que se transmitieron por vía de mejora. En nuestra zona de estudio, a diferencia de lo que ocurría en Castilla, no se mejora en todo lo permitido, ya que, tan solo se mejora en el remanente del quinto. Ibidem, p. 177-178.

${ }^{60}$ Según la legislación castellana Lib. X, Tít. VI, Ley II (Ley 18 de Toro): La mejora del tercio se puede hacer al nieto, aunque sus padres vivan. Novísima Recopilación de la Leyes..., Op. cit.
} 
frente a un 30\%. Este aspecto cambiará, y así en la segunda mitad de siglo las diferencias entre uno y otro dejan de ser tan marcadas y pasan a estar más equilibradas pasando a ostentar la primacía el hombre con un $57,1 \%$ frente a la mujer con un $42,9 \%$ del total. Esto mismo ocurre en la zona castellana de Valladolid y alrededores, donde comienza el siglo con una superioridad femenina y acabó con un claro predominio masculino, aunque mucho menos acentuado ${ }^{61}$ con relación a los valores que se dan en la comarca de Sahagún. De este modo, comprobamos la importancia de la mujer en aquellas sociedades en todo lo referente a cuestiones patrimoniales y hereditárias, pasando a ser la persona que aglutina aquellos bienes que los progenitores intentaban transmitir a sus descendientes sin dividirlos, como podía ser la casa familiar y algunos de los bienes raíces.

Por lo que respecta a la adjudicación de las diferentes mejoras entre los sexos, se aprecia como, en la primera mitad de siglo el predominio de la mujer en las mejoras conjuntas de tercio y quinto es apabullante $(90 \%)$ con relación al hombre $(10 \%)$, situación ésta que cambia en la segunda mitad donde se equilibran los datos para hacerse con la primacía el genero masculino. La evolución de la mejora del tercio y del quinto es totalmente diferente. Así en el tercio, se pasa de un equilibrio en la primera mitad de siglo a una preponderancia de la mujer $(66,7 \%)$ y en el quinto, la superioridad la ostenta el hombre $(71,4 \%)$. Así termina el siglo con una tendencia a dejar el tercio a la mujer y el quinto o remanente del quinto, al hombre.

En conclusión, en una primera mitad de siglo se pretendía mejorar a hijas menores, viudas, solteras, etc., como una forma de compensar su estado y de intentar romper el igualitarismo que, al contrario de lo que se pensaba, estaba creando una desigualdad manifiesta en ciertos estratos familiares ya aludidos y que con este tipo de actuaciones igualaban su situación con la de los demás hermanos que, por estar casados, ser mayores, haber recibido bienes por medio de donaciones, etc., estaban en una situación económicamente más boyante ${ }^{62}$. Muchas de estas actuaciones no serán entendidas por los demás hermanos y originarán numerosos pleitos, cuyo estudio conformaría otro apartado que, por su extensión, no puedo tratarlo en este trabajo. El siglo acabará con un mayor equilibrio entre ambos sexos.

${ }^{61}$ Valores de $60 \%$ para las mujeres y $40 \%$ para los hombres. GARCÍA FERNÁNDEZ, M. (1995). Herencia y patrimonio familiar en la Castilla..., Op. cit., pp. 168-170.

${ }^{62}$ Ibidem. 


\section{LAS MOTIVACIONES DE LA 'MEJORA'.}

Cuando un ser humano lleva a cabo un determinado acto siempre hay una motivación para ello y muchas veces se escuda en algún tipo de motivación trivial para encubrir otra intencionalidad que va más allá de la mera apariencia que se está ofreciendo ante la que no cabe discusión alguna. Otras veces, por el contrario, las motivaciones apuntadas son estrictamente personales y entran dentro del campo sentimental de la persona que la realiza. Por lo tanto, debemos de analizar cuáles son las verdaderas motivaciones que los individuos tienen para mejorar a una persona y averiguar, en la medida de lo posible, la veracidad de las mismas y si éstas encubren otras intenciones que nos orienten hacia una determinada estrategia familiar.

Cuadro 8. Motivaciones de las mejoras. 1700-1820.

\begin{tabular}{lccccccccc}
\hline & \multicolumn{7}{c}{ Persona que mejora/Persona mejorada } \\
\cline { 2 - 9 } \multicolumn{1}{c}{ Motivación } & 6 & 75,0 & 4 & 33,3 & 34 & 94,4 & 44 & 78,6 \\
\cline { 2 - 9 } & $N^{o}$ & $\%$ & $N^{o}$ & $\%$ & $N^{o}$ & $\%$ & $N^{o}$ & $\%$ \\
\hline Sin motivo & 2 & 25,0 & 6 & 50,0 & 0 & 0,0 & 8 & 14,3 \\
Por el cariño & 0 & 0,0 & 2 & 16,7 & 0 & 0,0 & 2 & 3,6 \\
Buena unión con conyuge & 0 & 0,0 & 0 & 0,0 & 2 & 5,6 & 2 & 3,6 \\
Para criar al hijo menor & 8 & 100,0 & 12 & 100,0 & 36 & 100,0 & 56 & 100,0 \\
\hline Total & & & &
\end{tabular}

FUENTE: Testamentos y escrituras de mejora. Protocolos Notariales. AHPL.

Más de $3 / 4$ del total de las mejoras que se realizan no se especifican el motivo que ha llevado al testador a hacerla. Del resto, el 18\% tiene un componente afectivo y de fidelidad al matrimonio. Por grupos, en primer lugar, cuando la mejora se realiza sobre los hijos no se especifica ningún tipo de motivación para llevar a cabo la misma (94\%), lo que nos da ha entender que no se necesita ninguna excusa o motivo, porque lo que prima en estos casos es la estrategia a seguir dentro del grupo familiar, que puede ir encaminada a un intento por impedir la dispersión patrimonial o como una forma de redistribución más equitativa de los bienes atendiendo a las necesidades de los hijos. En un 5,6\% de los casos la motivación más extendida tiene que ver con el cuidado de algunos de los hijos de corta edad que tenga el matrimonio ${ }^{63}$. Será ahora cuando entran en juego los curadores o

${ }^{63}$ Así aparece: ...mejoro a... para ayuda de criarse por su corta vida..., AHPL, Bartolomé Álvarez, Caja 4433. 
tutores que se encargarán de velar por ese patrimonio al igual que por el bienestar del menor. Por lo tanto, entre padres e hijos la motivación afectiva no se deja traslucir en las mejoras.

Por el contrario, cuando el beneficiario de la mejora es el cónyuge que ha quedado vivo se producen dos circunstancias: por un lado, que no se especifique la motivación de la misma (33,3\% cuando el mejorado es el marido o $75 \%$ cuando lo es la mujer) y por otro que sí se haga. Cuando se explica la motivación, ésta suele ser de tipo afectivo $(50 \%)^{64}$ cuando la mujer es la testadora, y se reduce a la mitad cuando lo es el marido. Si ponemos en relación éstos dos últimos parámetros podemos concluir que el marido no se siente en la obligación de dar ningún tipo de motivación para mejorar a su esposa, aspecto éste contrario a lo que ocurre con ella (75\% frente al 33\% respectivamente). La mujer pasa a demostrar una mayor afectividad y cariño por su pareja. Aunque, en ambos casos es una prueba de reconocimiento del amor, no podemos olvidar que además es un ingreso patrimonial que va a parar al caudal del cónyuge pero no hemos encontrado ningún indicio, en las escrituras de testamento, en el que se pueda entrever otro tipo de estrategia o motivación de no ser la meramente afectiva. También se premia la fidelidad en el matrimonio y el buen funcionamiento del mismo, ya que casi el $17 \%$ de las mejoras lo hacen. Así el amor, el cariño, el cuidado en las enfermedades, el interés, la fidelidad, etc., conformaron las motivaciones por las que los testadores del siglo XVIII premiaban a sus herederos ${ }^{65}$.

Por lo que respecta a las condiciones ${ }^{66}$ que los testadores imponían para poder percibir la mejora podemos decir que en esta zona son inexistentes, si exceptuamos aquella que limita la posesión de los bienes mientras viva la persona mejorada, es lo que se conoce como el usufructo de un determinado patrimonio, que, generalmente, volverá a tronco familiar del cual había salido. Esta condición se indica cuando la persona mejorada es el otro cónyuge con el fin de evitar una

${ }^{64}$ Por ejemplo... mejoro a mi marido en el remanente del quinto de mis bienes por el mucho amor y cariño que la tengo.... AHPL, Jerónimo de la Mata, Caja 4437 y ...mando el quinto de mis bienes a D. Joseph Brezosa mi marido por la buena unión que conmigo hizo..., AHPL, Antonio Escalante López, Caja 4495.

${ }^{65}$ García Fernández, M. (1995). Herencia y patrimonio familiar en la Castilla..., Op. cit., pp. 176

${ }^{66}$ Según las leyes castellanas excepto en la legitima se puede poner unas condiciones cuyo cumplimiento sería necesario para poder recibir lo que en ella se expresa. Sexta Partida, Tít. IX, Ley XXI. Nos explica como en las mandas se pueden poner condiciones. Ley XI. Cómo el padre no puede poner condición ninguna en la legitima que deja a su hijo. Siete Partidas del sabio rey Don Alfonso..., Op. cit. 
dispersión patrimonial que perjudicaría al resto de la familia. Esto no ocurre en la zona vallisoletana donde las condiciones impuestas para el beneficio de la mejora son muy variadas ${ }^{67}$ y tienen ramificaciones que afectan a otros miembros de la familia que pueden ser beneficiados por esa mejora indirectamente ${ }^{68}$.

\section{'MEJORAS': ¿IMPOSICIÓN O ESTRATEGIA?}

Cuadro 9: Tipología del bien sobre el que recae mejora.1700-1820.

\begin{tabular}{|c|c|c|c|c|c|c|c|c|c|c|c|c|}
\hline \multirow[b]{3}{*}{ Bienes } & \multicolumn{12}{|c|}{ Persona mejorada } \\
\hline & \multicolumn{2}{|c|}{ Cónyuge } & \multicolumn{2}{|c|}{ Un hijo } & \multicolumn{2}{|c|}{ Varios hijos } & \multicolumn{2}{|c|}{ Yerno } & \multicolumn{2}{|c|}{ Nietos } & \multicolumn{2}{|c|}{ Total } \\
\hline & $N^{o}$ & $\%$ & $N^{o}$ & $\%$ & $N^{o}$ & $\%$ & $N^{o}$ & $\%$ & $N^{o}$ & $\%$ & $N^{o}$ & $\%$ \\
\hline A & 5 & 23,8 & 8 & 24,2 & 0 & 0,0 & 0 & 0,0 & 0 & 0,0 & 13 & 19,7 \\
\hline $\mathrm{B}$ & 1 & 4,8 & 0 & 0,0 & 0 & 0,0 & 0 & 0,0 & 0 & 0,0 & 1 & 1,5 \\
\hline C. & 15 & 71,4 & 25 & 75,8 & 7 & 100,0 & 2 & 100,0 & 3 & 100,0 & 52 & 78,8 \\
\hline Total & 21 & 100 & 33 & 100,0 & 7 & 100,0 & 2 & 100,0 & 3 & 100,0 & 66 & 100,0 \\
\hline
\end{tabular}

A, Casa; B, Animales de tiro; C, Bienes muebles y raíces.

FUENTE: Protocolos Notariales (Sahagún). AHPL.

La mejora no deja de ser un ingreso material que va a parar al patrimonio de la persona mejorada y que, en muchas ocasiones, marca algún tipo de estrategia familiar, sobre todo cuando deja marcados los bienes sobre los que el testador quiere que se aplique la mejora $(21,2 \%)^{69}$. Pero la mayoría de las veces las mejoras se realizan sobre el total de los bienes sin precisar concretamente sobre cuales $(78,8 \%)^{70}$.

El Cuadro 9 nos indica una tendencia bastante común en esta zona. Así en muchas de las mejoras que se realizan van impuestos los bienes sobre los que debe de aplicarse como una forma de intentar marcar una trayectoria, que anteriormente

${ }^{67}$ Van desde el pago de funerales del difunto, no pedir cuentas del salario que los adeudan, renunciar a alguna parte de otros bienes como los gananciales, etc., GARCÍA FERNANDEZ, M. (1995). Herencia y patrimonio familiar en la Castilla..., Op. cit., p. 176-177

${ }^{68}$ Puede ser el caso de satisfacer las necesidades de algún otro hermano mediante el pago de los estudios, cuidado de algún menor, etc., Ibidem, p. 177.

${ }^{69}$ Lib. X, Tít. VI, Ley III (Ley 19 de Toro). Trata de cómo se puede asignar de la mejora de tercio y quinto en cierta parte de bienes de la herencia. Novísima Recopilación de la Leyes ..., Op. cit.

${ }^{70}$ En la zona castellanas de las localidades circundantes a Valladolid este dato baja al $70 \%$ las mejoras que no precisan el bien sobre el que recae pero sube al $84 \%$ en la propia ciudad de Valladolid. García Fernandez, M. (1995). Herencia y patrimonio familiar en la Castilla..., Op. cit. pp. 169 y 174. 
ya se esbozo ${ }^{71}$. Con estos datos, en primer lugar, podemos decir que la vivienda se constituye como un bien material importantísimo para la continuación de la vida familiar, siendo uno de los pilares principales sobre el que se asienta el resto de relaciones familiares. Por este motivo, los testadores intentan que no se divida la casa entre los hijos mediante la utilización de la mejora (20\%) y así que pase íntegra a la persona mejorada. Cuando no se emplea esta via, es utilizada la manda testamentaría con el mismo fin: evitar la fragmentación de la casa ${ }^{72}$. Por eso, ésta forma parte de las mejoras efectuadas al cónyuge en un 23,8\% de los casos. Este aspecto, juega un papel esencial cuando la beneficiaria es la mujer, ya que, a la muerte del marido la casa constituye para ella un bien imprescindible para su supervivencia porque, si ésta se repartiese entre los hijos, se correría el peligro de que éstos la despojaran de dicho bien, quedando la viuda al amparo de su suerte, máxime si las relaciones con sus hijos no han sido satisfactorias. Por lo tanto, la mejora pasa a convertirse en un arma contra herederos disconformes ${ }^{73}$. Además para la mujer la casa asegura la posibilidad de criar a sus hijos menores bajo unas mínimas condiciones cuando fallezca el marido. En la zona castellana de Valladolid y alrededores la casa es legada de esta forma en el 3,27\% de los casos, muy por debajo que en nuestra zona ${ }^{74}$.

En muchas ocasiones nos encontramos con ciertas limitaciones a la hora de disfrutar de estos bienes, ya que suelen ser adjudicados por medio del usufructo, es decir, mientras viva el beneficiario de los bienes a quién han sido legados, cortando así la posibilidad de que parte del patrimonio familiar acabase en manos ajenas al tronco de procedencia ${ }^{75}$. De este modo, serán los herederos del testador quienes acaben beneficiándose de este patrimonio una vez que fallezca el progenitor. En

${ }^{71}$ Así aparece en algunos testamentos: ... mejoro a Maria Phelipe mi mujer en todo lo que este permitido en el quinto de mi hacienda y se lo den en la casa donde vivimos..., AHPL, Jerónimo de la Mata, Caja 4437. Otras veces la escritura no especifica los bienes exactos y alude a cualquier bien mueble o inmueble por lo que la precisión a la hora de fijar los bienes es menos exacta.

72 ... mando a Marcelo Prado mi marido la mitad de la casa donde vivo por los días de su vida..., AHPL, José Antonio García Siero, Caja 4531.

${ }^{73}$ Esto mismo ocurre en zona castellana de Valladolid y alrededores donde la percepción de este tipo de beneficios podría ocasionar discordias entre los demás herederos. GARCía FERNÁNDEZ, M. (1995). Herencia y patrimonio familiar..., Op. cit., p. 168.

${ }^{74}$ En la zona de Valladolid primaría el dinero y las joyas con casi un $15 \%$ del total. Ibidem, p.170. En la zona valisoletana la diversidad y especificación de bienes sobre los que recae la mejora es mucho mayor que en nuestra comarca leonesa. Dinero y joyas, tierras, ropa, etc., forman un amplio abanico de posibilidades a la hora de mejorar que no aparecen en Sahagún y comarca.

75 ... mando a Pedro Ramos la mitad de la casa en donde vivo por los días de su vida y luego venga a mis herederos..., AHPL, José Antonio García Siero, Caja 4531. 
cualquier partija de bienes, testamentos, etc., la casa aparece en un lugar privilegiado dentro del computo global de los demás bienes y siempre suele ser el primer bien que se recibe en las hijuelas ${ }^{76}$. Después de la casa, el resto de los bienes muebles y raíces que no se precisarían, acapararán, en el 71,4\% de los casos, las mejoras de esta zona.

Por lo que respecta a las mejoras realizadas a uno de los hijos, en $3 / 4$ de los casos recae sobre bienes muebles y raíces y el resto sobre la casa, intentando impedir la división de la misma entre sus hermanos. Suele estar motivado por actuaciones que van encaminadas a buscar la primacía del hijo que ha renunciado a independizarse para seguir en casa de sus padres con el objetivo de cuidarles hasta el momento de la muerte. Con estas prácticas se pretende evitar el igualitarismo que propugna la ley, haciendo que uno de los hijos reciba un número mayor de bienes respecto al resto de hermanos con un fin determinado que va desde el establecimiento de una primogenitura hasta la forma en que los padres tienen de asegurarse que uno de sus hijos les cuide en los últimos días de su vida. Por el contrario, cuando los beneficiarios de las mejoras son varios hijos desaparece la prioridad de mejorar sobre la casa porque ello originaría la división y reparto de la misma y por consiguiente su desmembración. Así se realiza sobre cualquier bien mueble o raíz dejando fuera la casa, que es legada a una sola persona por medio de una manda testamentaria, donación o legado ${ }^{77}$.

En conclusión, en el reparto de la herencia se impone el igualitarismo frente a la mejora post mortem, aunque el porcentaje de las veces que ésta se utiliza en la Comarca de Sahagún es muy superior al de otras zonas próximas como la vega del Esla o en Valladolid, siendo hijos y cónyuges los individuos que más se benefician de ellas. La mejora pasa a ser un instrumento que tiene una gran repercusión en aquellas familias en las que se aplica, porque al control que supone su utilización se une la voluntad intencionada de dirigir la familia en un determinado sentido, aquel que el testador considere el más idóneo para conseguir el fin último de todo el proceso: mantener o mejorar la posición social que han conseguido los antecesores, es decir, la reproducción social del sistema ${ }^{78}$. Será en el marco de este concepto en el que se inserta la importancia de las mejoras en sus diferentes ámbitos y personas sobre las que recae que, en una primera visión superficial, lo

${ }^{76}$ AHPL, Jacinto Villanueva, Caja 4388.

77 Se pretende que los bienes más preciados para aquellas gentes no se salgan de la herencia patrilineal premiando a las personas, por medio de mejoras, mandas, donaciones, etc., que ayudan a que este hecho se produzca.

${ }^{78}$ FERRER I Alos, Ll. Notas sobre el uso de la familia..., Op. cit., pp. 16-17. 
que estaría provocando sería una ruptura del igualitarismo vigente en el derecho castellano, pero que, como hemos comprobado, lo que origina es una verdadera redistribución y adaptación de los bienes a las necesidades de cada una de las personas a las que van destinados esas propiedades. 
